\title{
A Guide for Entrepreneurs Who Lead and Manage Change Llynne Plante
}

\author{
"When you are a young startup, the one thing you" \\ cannot be afraid of is change - because change \\ happens all the time. \\ Tariq Zaid \\ CEO of Select Start Studio
}

\begin{abstract}
To grow a business, entrepreneurs must know how to lead and manage change. However, the change management literature offers little in the way of specific, practical advice that leaders can use to guide their actions. This article builds on a review of the change management literature, a small field study, and years of experience supporting technology companies. It identifies and describes the top nine leadership actions (and their associated behavioural traits) that technology entrepreneurs who lead and manage change should carry out.
\end{abstract}

\section{Introduction}

A fundamental reason that organizations undergo change is to survive and grow; hence managing change becomes a priority for all founders and entrepreneurs. Key to survival is adaptability, or the ability to effectively and efficiently change business models, business processes, and technologies in response to disruptive innovations and competitive threats in a rapidly evolving environment. Entrepreneurs must then be armed with the right knowledge to ensure successful execution of change tactics as they seek to adapt their growth strategies in response to competitive, economic and technological pressures.

Much has been written about change management and the role and behaviours of the Chief Executive Officer (e.g., Eisenbach et al., 1999: tinyurl.com/6vrpgmj; Higgs and Rowland, 2005: tinyurl.com/7g55tmu; Miller, 2002: tinyurl.com/7wlkn56; Ahn et al., 2004: tinyurl.com/7d9qfzq). Studies link leadership to the change management process (e.g., Kotter, 1995: tinyurl.com/84of2p4; Higgs and Rowland, 2005). Process-based change models, from Lewin's three-step model (Burnes, 2004; tinyurl.com/7qrqsez) to Kotter's eight-step process (Kotter, 1995), make the leader responsible for the successful management of change.
However, technology entrepreneurs may find the change management literature confusing with a plethora of lists of actions and processes that primarily focus on change in large organizations. Furthermore, a review of the change management literature revealed that up to $70 \%$ of change initiatives fail or underperform and that the role and behaviours of leaders of change are largely associated to the success and failure of change initiatives (Miller, 2002: tinyurl.com/7wlkn56; Higgs and Rowland, 2005: tinyurl.com/7g55tmu).

In this article, the top nine leadership actions that a technology entrepreneur must undertake when leading and managing a change initiative are summarized based on a broad review of change management literature. For each action, behavioural traits that enable effective leadership are identified because behaviour is intrinsically linked to the effectiveness and success of action. A field study was carried out to validate the identified actions and to map behavioural traits to actions. The results of the field study included five indepth interviews (two entrepreneurs, two executives of a large organization, and one employee) and nine responses to a survey completed by employees of a large organization. 


\section{A Guide for Entrepreneurs Who Lead and Manage Change}

\section{Llynne Plante}

Table 1 lists the nine leadership actions and their corresponding behavioural traits that an entrepreneur who wishes to increase the likelihood of success of leading change must carry out. The order does not represent a sequence of action or a process. The sections that follow provide greater detail about each of these actions and their associated behavioural traits, including related insights from the literature.

\section{Communicate the Change}

To build commitment and buy-in, an entrepreneur who leads change much communicate their big picture or vision clearly and consistently (Fedor et al., 2008: tinyurl.com/7649p9m; Kotter, 1995: tinyurl.com/84of2p4). The job of bringing the vision to life rests with the entrepreneur as they share their mission, goals, and objectives and build a sense of accomplishment throughout the organization (Hesselbein, 2000; tinyurl.com/7rkor63). The leader must also build a vision of the future that can be easily communicated to customers, employees, and other stakeholders (Kotter, 1995). A critical component of communicating the vision is providing stakeholders with a roadmap for the implementation of the change strategy (Elrod and Tippett, 2002; tinyurl.com/7r5v2vb).

Two behavioural traits of leaders that are closely associated with communicating change are consistency and instrumentality (defined as the ability to plan, structure, implement, and control). To align the organization, employees must receive consistent messages from the owner-entrepreneur (Mohrman, 1999; tinyurl.com/ 7nko56t). Communication consists of both words and actions (Kotter, 1995; tinyurl.com/84of2p4); inconsistency between the two will quickly lead to stakeholder cynicism and undermine the change (Miller, 2002; tinyurl.com/7wlkn56). In a large or strategic change, the entrepreneur requires significant instrumental skills for successful execution (Nadler and Tushman, 1989; tinyurl.com/7g7zdvm); as such, an entrepreneur's communications must be deliberate, planned, focused, engaging, and purposeful.

Table 1. Actions and behavioural traits to lead and manage change

\begin{tabular}{|c|c|c|}
\hline \multicolumn{2}{|c|}{ Actions } & \multirow{2}{*}{$\begin{array}{l}\text { Behavioural Traits } \\
\text { Consistency and instrumentality } \\
\text { • Instrumentality } \\
\text { - Consistency }\end{array}$} \\
\hline 1 & $\begin{array}{l}\text { Communicate the change } \\
\text { - } \quad \text { Create clarity } \\
\text { - } \quad \text { Provide a roadmap }\end{array}$ & \\
\hline 2 & $\begin{array}{l}\text { Create a vision } \\
\text { - Create motivation and excitement } \\
\text { - Create belief in the change } \\
\text { Own the change }\end{array}$ & $\begin{array}{c}\text { Confidence and courage } \\
\text { - } \quad \text { Ability to enable } \\
\text { - } \quad \text { Credibility } \\
\text { - Commitment }\end{array}$ \\
\hline 3 & Identify and mobilize change agents & Ability to enable \\
\hline 4 & Engage at all levels & Integrity and trustworthiness \\
\hline 5 & Mind the culture & Self-awareness and mindfulness \\
\hline 6 & Mind the people & Integrity, consistency, and fairness \\
\hline 7 & $\begin{array}{l}\text { Plan and manage the change process } \\
-\quad \text { Measure } \\
\text { - Create alignment }\end{array}$ & $\begin{array}{l}\text { Perseverance } \\
\text { • Instrumentality } \\
\text { - Instrumentality }\end{array}$ \\
\hline 8 & Build organizational skills and capacity & Instrumentality \\
\hline 9 & Adapt to the environment & Ability to synthesize \\
\hline
\end{tabular}




\section{A Guide for Entrepreneurs Who Lead and Manage Change}

\section{Llynne Plante}

\section{Create a Vision}

The ability of the entrepreneur to create a vision of the future has been identified as a central component of successful transformational change (Hesselbein, 2000: tinyurl.com/7rkor63; Ahn et al., 2004: tinyurl.com/7d9qfzq; Eisenbach et al., 1999: tinyurl.com/6vrpgmj; Kotter, 1995: tinyurl.com/84of2p4; Higgs and Rowland, 2005: tinyurl.com/7g55tmu). To be effective, this vision must provide a greater sense of purpose; encourage dissatisfaction with the status quo; and motivate, engage, and excite stakeholders. The entrepreneur must internalize that vision and truly believe in it. The vision provides clarity of direction for the organization and acts as a guidepost for decision making and for the alignment of the organization's business processes and systems, structure, and shorter term objectives (Kotter, 1995).

The five behavioural traits of leaders that are associated with vision creation are: confidence, courage, ability to enable, credibility, and commitment. Most of these behavioural traits have been linked to transformational leadership (Nadler and Tushman, 1989: tinyurl.com/ 7g7zdvm; Miller, 2002: tinyurl.com/7wlkn56).

Personal courage and confidence are often associated with leadership (Miller, 2002: tinyurl.com/7wlkn56) because managing and sustaining a transformational change initiative is hard work, is very demanding, and can be a highrisk undertaking both for the organization and the reputation of the entrepreneur (Ahn et al., 2004: tinyurl.com/7d9qfzq; Drucker, 2006: tinyurl.com/7vufkzp). Enabling others through frequent communication, training, empathy, listening, and mentoring is a way for an entrepreneur to resolve employees' uncertainty about the change process and enhance their capacity for dealing with the change effort (Eisenbach et al., 1999: tinyurl.com/ 6vrpgmj; Nadler and Tushman, 1989: tinyurl.com/ 7g7zdvm). Credibility through personal experience is a central factor linked to employees' positive belief in a change initiative (Miller, 2002). Finally, an entrepreneur leading change must be committed and engaged in the change process and cannot delegate that responsibility or accountability to others (Ahn et al., 2004; Miller, 2002).

\section{Identify and Mobilize Change Agents}

Entrepreneurs need to engage others to build a core team to drive a change forward (Kotter, 1995; tinyurl.com/84of2p4). They engage people by encouraging participation, rewarding success, and replacing those unwilling or unable to make the change (Miller, 2002; tinyurl.com/7wlkn56).
The key behavioural trait of leaders that are associated with identifying and mobilizing change agents is the ability to enable. The entrepreneur enables his change agents to mobilize the change by setting challenging goals, by providing personal support, by encouraging team-decision making, and by encouraging people to take risks (Eisenbach et al., 1999: tinyurl.com/6vrpgmj; Fedor et al., 2008: tinyurl.com/7649p9m; Mohrman, 1999: tinyurl.com/7nko56t).

\section{Engage at All Levels}

An entrepreneur will first outline the vision of the future and then engage groups of employees at different levels to help add detail to the vision and develop an implementation plan; this process builds commitment among team members (Higgs and Rowland, 2005; tinyurl.com/7g55tmu), as well as a sense of ownership . Buyin achieved through engagement has been positively linked to the discretionary effort of individuals (Choi, 2011; tinyurl.com/7bn3xw6) and hence can be crucial to maintaining productivity during turbulent times. Furthermore, the probability of changes taking root increases when individuals can participate in the decision making on how the change will be implemented (Schneider et al., 1996; tinyurl.com/6nh4mzo).

The behavioural trait of leaders that is associated with engaging individuals at all levels is trustworthiness. Today's organizations are built on trust and therefore leaders must take responsibility for establishing trust-based relationships. Change introduces significant uncertainty, so trust is fundamental to successful engagement (Mohrman, 1999; tinyurl.com/7nko56t), can increase individual readiness for change (Choi, 2011; tinyurl.com/7bn3xw6), and can reduce resistance to change (Self and Shraeder, 2008; tinyurl.com/7vjp9nx).

\section{Mind the Culture}

Organizational culture refers to the norms, deeply held beliefs, and assumptions that develop through shared history and experiences (Schein, 1990; tinyurl.com/7vma5w7). Culture is difficult to change (Schneider et al., 1996; tinyurl.com/6nh4mzo) because it is difficult to understand and measure (Schein, 1990), making it a central challenge for entrepreneurs who lead transformational change.

However, changing the behaviour of people is the most important challenge in implementing change. To be successful, a change effort in a technical firm must influence emotions as well as thoughts (Deutschman, 2005; tinyurl.com/7d37z). 


\title{
A Guide for Entrepreneurs Who Lead and Manage Change
}

\author{
Llynne Plante
}

To change organizational culture and behaviours, the entrepreneur can articulate new values and norms for the firm and use multiple levers, such as modeling the desired values or aligning reward structures and management processes (Fitzgerald, 1988; tinyurl.com/8xz4nef). Through policies, compensation, rewards, practices, and routines, the entrepreneur can create a climate to enable and reward the enactment of desired values and behaviours (Schein, 1990: tinyurl.com/7vma5w7; Schneider et al., 1996: tinyurl.com/6nh4mzo; Tushman and O’Reilly, 1996: tinyurl.com/7y8lhm6). The technology entrepreneur must also create an organizational mind-set and culture that are receptive to change; this results in an organization that sees change as an opportunity rather than a threat (Drucker, 2000; tinyurl.com/7rkor63).

The two behavioural traits of leaders that are associated with actions to mind the culture are self-awareness and mindfulness. Entrepreneurs must not only espouse the desired values and behaviours underpinning their change efforts, they must also enact them (Eisenbach et al., 1999: tinyurl.com/6vrpgmj). To be effective, entrepreneurs need to know who they are and what role they should play in different situations. Essentially, entrepreneurs need to adopt different personalities depending on the circumstance (Pettigrew, 1987; tinyurl.com/6uzvtbl).

\section{Mind the People}

Change is about people and, as a result, change may cause "people issues". Change is an emotional experience for most individuals given that it often involves substantial changes in roles, responsibilities, relationships, which can significantly impact an individual's capacity to learn new behaviours and skills during a transition process. Fundamentally, employees do not resist technical change; they resist changes in the human relationships that typically accompany technical changes (Lawrence, 1969; tinyurl.com/83v89wn).

The behavioural traits of leaders that are associated with actions to mind the people are consistency and integrity. Entrepreneurs must show consistency in the values they espouse and the values they enact (Eisenbach et al., 1999: tinyurl.com/6vrpgmj). Often, this is referred to as the need for leaders to "walk the talk". Integrity and fairness are also closely linked to employee commitment at work, as well as the degree to which values are held and followed (Leader to Leader: The Integrity Connection, 2000; tinyurl.com/7rkor63). In change, the integ- rity and fairness of leadership will take centre stage given that employees look to their leaders for guidance, direction, clarity, and understanding (Lawrence, 1969: tinyurl.com/83v89wn; Eisenbach et al., 1999), which makes those values critical to employee engagement, commitment, and retention.

\section{Plan and Manage the Change Process}

Entrepreneurs must remain closely in touch during the design and implementation steps of a change (Miller, 2002; tinyurl.com/7wlkn56). Leading change cannot be delegated and the entrepreneur who leads the change must own the process that brings about the change (Cummings, 1999; tinyurl.com/7nko56t). Entrepreneurs monitor change progress closely and take responsibility for internal and external commitment building (Miller, 2002). They align organizational structures, business processes, and systems to maximize results (Eisenbach et al., 1999: tinyurl.com/6vrpgmj; Pettigrew et al., 2001: tinyurl.com/6uzvtbl; Ahn et al., 2004: tinyurl.com/7d9qfzq).

The behavioural traits of leaders that are associated with planning and managing the change process are instrumentality and perseverance. Effective entrepreneurs provide more than charisma and vision; they focus on structure, implementation, execution, efficiency, and goal-setting (Rosing et al., 2011: tinyurl.com/72eyvmv; Nadler and Tushman, 1989; tinyurl.com/7g7zdvm). An entrepreneur must be persistent and relentless in maintaining commitment and sustaining the change effort long enough to realize the vision and the benefits sought (Miller, 2002; tinyurl.com/7wlkn56).

\section{Build Organizational Skills and Capacity}

Large-scale change cannot be managed by the entrepreneur alone. The effective leader focuses on building the leadership capacity, capability, and skills of senior staff, and ensures effective systems and managerial processes are in place (Nadler and Tushman, 1989: tinyurl.com/7g7zdvm; Self and Shraeder, 2008: tinyurl.com/7vjp9nx). Pushing leadership of strategic change throughout the organization increases engagement at all levels, thereby increasing the probability of success (Nadler and Tushman, 1989). Providing employees with opportunities to learn and develop new skills will also build a culture of inventiveness and improvisation that bolsters the organization's resilience (Coutu, 2002; tinyurl.com/82bwxvu). 


\section{A Guide for Entrepreneurs Who Lead and Manage Change}

\section{Llynne Plante}

\section{Adapt to the Environment}

In complex and turbulent environments, entrepreneurs cannot predict the future with accuracy and have little control over economic fluctuations, political events, industry restructuring, or competitive forces and technological discontinuities (Dunphy and Stace, 1988; tinyurl.com/70j89ey). Entrepreneurs must be adept at recognizing patterns in chaos, identifying trends, knowing what inputs to disregard, and refining possibilities as additional data become available. Entrepreneurs must make sense of the external environment to formulate strategies (Maitlis and Sonenshein, 2010; tinyurl.com/ 7 ctanxy) as well as to adapt strategies to respond to changes in their business environment.

The behavioural trait of leaders that is associated with adapting to the environment is the ability to synthesize. An effective leader of change synthesizes new strategies or course corrections by interpreting discrepant clues from the environment (Maitlis and Sonenshein, 2010; tinyurl.com/7ctanxy).

\section{Conclusion}

This article describes nine key leadership actions and corresponding behavioural traits that are associated with successful change leadership. Change can be complex and, as such, it will always be a challenge for entrepreneurs. Successful entrepreneurs adapt their leadership approach to the specific strategic situation they are facing rather than rely on a single style.

This article's contributions are that: i) it maps behavioural traits to specific actions that leaders must carry out in a change process and ii) it provides a framework that can be useful to an entrepreneur who needs to implement a change strategy.

Future research can explore key leadership actions and behaviours actually adopted by founders of growth-oriented technology companies.

\section{About the Author}

Llynne Plante is Regional Director for Eastern and Northeastern Ontario with the Industrial Research Assistance Program of the National Research Council Canada (NRC-IRAP). Llynne has a strong experience in finance, international business, $R \& D$, and technology entrepreneurship from both the private and public sectors. Prior to joining NRC-IRAP, Llynne worked at Public Works Government Services Canada (PWGSC), at Export Development Canada, and in business and engineering roles in small Canadian technology firms. Llynne holds an EMBA from Queen's University in Kingston, Canada.

Citation: Plante, L. 2012. A Guide for Entrepreneurs Who Lead and Manage Change. Technology Innovation Management Review. March 2012: 27-31. (cc) BY 